\title{
Tipos de cobertura do solo e épocas de colheita na produção de melissa
}

\author{
Luiz Antonio Biasi; Ana Paula de J Kowalski; Diana Signor; Márcia A Alves; Francine I de Lima; Cícero \\ Deschamps
}

UFPR, C. Postal 19061,81531-990 Curitiba-PR; biasi@ufpr.br; ana_agro@hotmail.com; disignor@hotmail.com; alves_m2003@yahoo. com.br; francineufpr@hotmail.com; cicero@ufpr.br

\section{RESUMO}

Avaliou-se o efeito de diferentes tipos de cobertura do solo e épocas de colheita sobre a produção de biomassa e o rendimento de óleo essencial de Melissa officinalis. O experimento foi conduzido na Estação Experimental do Canguiri da UFPR, no município de Pinhais-PR, de novembro de 2005 a maio de 2006. Os tratamentos testados foram acículas de pinus, plástico preto e a testemunha sem cobertura. O delineamento experimental foi em blocos ao acaso em arranjo de parcelas subdivididas no tempo, com seis repetições e 20 plantas por parcela. Foram feitas três colheitas, aos 84, 134 e 191 dias após o plantio, sendo o corte dos ramos feito a $10 \mathrm{~cm}$ do solo. Foram avaliados a massa fresca e seca por planta e por hectare e o teor de óleo essencial por hidrodestilação. Não houve efeito significativo da interação entre coberturas do solo e épocas de colheita sobre as características analisadas. Houve decréscimo na produção de biomassa na terceira colheita, uma vez que o rendimento médio de massa seca que foi de 976 e $1135 \mathrm{~kg} \mathrm{ha}^{-1}$ na primeira e segunda colheitas, respectivamente, reduziu para $781 \mathrm{~kg} \mathrm{ha}^{-1}$ na terceira. $\mathrm{O}$ rendimento de óleo essencial também reduziu com as colheitas sucessivas, cujos valores médios foram de 4,$63 ; 2,97$ e $0,43 \mathrm{~L} \mathrm{ha}^{-1}$ na primeira, segunda e terceira colheitas, respectivamente. Concluiu-se que a cobertura do solo com acículas de pinus e plástico preto não interferiram no rendimento de biomassa e de óleo essencial da $M$. officinalis. O crescimento e o acúmulo de óleo essencial da $M$. officinalis reduzem nas colheitas realizadas no outono na região de Pinhais-PR.

Palavras-chave: Melissa officinalis, planta medicinal, óleo essencial, cobertura morta.

\section{ABSTRACT \\ Types of mulching and harvesting time on lemon balm production}

The effect of covering and harvesting time on biomass production and essential oil production of Melissa officinalis was evaluated. The experiment was carried out at the Estação Experimental de Canguiri, Pinhais, Paraná State, Brazil, from November 2005 to May 2006. The treatments included pine needles, black plastic and control without covering. The experimental design was of randomized blocks in split plot in time with six replications and 20 plants per experimental unit. Three harvests were performed (84, 134 and 191 days after planting), cutting the stems at $10 \mathrm{~cm}$ from the soil surface. The fresh and dry masses per plant and essential oil yield by hidrodestilation were determined. There was no significant effect of the interaction between the mulch and the harvesting time for the evaluated characteristics. A decrease in biomass production was observed at the third harvest, where the average of dry mass production was of 976 and $1135 \mathrm{~kg}$ $\mathrm{ha}^{-1}$ at the first and second harvest respectively, reducing to $781 \mathrm{~kg}$ $\mathrm{ha}^{-1}$ at the third harvest. The essential oil production also decreased with the successive harvests, being $4.63 ; 2.97$ and $0.43 \mathrm{~L} \mathrm{ha}^{-1}$ at the first, second and third harvest, respectively. The type of mulching did not interfere in biomass and essential oil production of $M$. officinalis. The vegetative growth and essential oil accumulation of $M$. officinalis decreased in the autumn harvest in Pinhais.

Keywords: Melissa officinalis, medicinal plant, essencial oil, mulch.

(Aceito para publicação em 29 de maio de 2008; aceito em 29 de junho de 2009)

(Received in May 29, 2008; accepted in June 29, 2009)

\begin{abstract}
$\mathrm{A}_{\mathrm{ve}}^{\mathrm{N}}$ Melissa officinalis L., erva-cidreira verdadeira ou melissa foi a quinta planta medicinal mais importante no Paraná, quanto ao valor bruto da produção, atingindo $\mathrm{R} \$ 1.222 .520,00$ na safra 2001/2002. A melissa é considerada espécie de boa rentabilidade, cuja renda bruta é estimada em R\$ 12.000,00 ha ${ }^{-1}$ $\mathrm{ano}^{-1}$, para um preço pago de $\mathrm{R} \$ 6,00$ $\mathrm{kg}^{-1}$ de matéria prima seca e produtividade de $2 \mathrm{t} \mathrm{ha}^{-1}$ ano $^{-1}$ (Corrêa Júnior \& Scheffer, 2004).

A planta é herbácea, perene, com caules ramificados desde a base, com 30 a $60 \mathrm{~cm}$ de altura. Suas folhas e inflorescências são utilizadas como aromatizantes de alimentos, fonte de
\end{abstract}

fragrâncias e para fins medicinais, sendo preparadas na forma de infusão. Dentre as plantas aromáticas, a melissa destaca-se pela peculiaridade de seu óleo essencial, rico em citral, citronelal, citronelol, limoneno, linalol e geraniol, possuindo ação bacteriostática. Devido à presença de taninos, apresenta ação virustática. As propriedades medicinais são calmante, contra dispepsia, estados gripais, bronquite crônica, cefaleias, enxaqueca, dores de origem reumática e para normalizar as funções gastrointestinais (Lorenzi \& Matos, 2002).

O óleo essencial está localizado em tricomas glandulares peltados que são encontrados em ambas as superfícies das folhas. Os tricomas capitados não possuem óleo essencial, apenas alguns lipídeos e carboidratos (Martins \& Pastori, 2004). Logo, torna-se importante avaliar como o sistema de cultivo pode interferir na produção de folhas e consequentemente na quantidade de óleo essencial produzido pela planta. Um dos tratos culturais inclui a cobertura do solo com materiais vegetais ou sintéticos. Consultando vários trabalhos realizados, observou-se que os resultados obtidos variam de acordo com os materiais de cobertura do solo empregados e as condições edafoclimáticas em que a cultura está sendo desenvolvida (Queiroga et al., 2002; Araújo et al., 2003; Negreiros 
et al., 2005).

Dentre as coberturas do solo mais utilizadas está o plástico preto, cujo uso resulta em aumento de produtividade; antecipação da colheita, devido ao aumento da taxa de desenvolvimento, que é proporcionada pela maior temperatura e menor amplitude térmica do solo coberto; redução da infestação por pragas e pelas doenças por elas disseminadas e controle de plantas invasoras (Galambosi \& Szebeni-Galambosi, 1992; Miranda et al., 2003). A proteção do solo com cobertura morta também apresenta vantagens semelhantes, como a redução da erosão e das perdas de nutrientes por lixiviação (Corrêa et al., 2003).

O objetivo deste trabalho foi avaliar a produção de biomassa e óleo essencial de melissa cultivada sob diferentes tipos de cobertura do solo em três épocas de colheita.

\section{MATERIAL E MÉTODOS}

O experimento foi desenvolvido entre setembro de 2005 e maio de 2006 , na Estação Experimental do Canguiri da Universidade Federal do Paraná, no município de Pinhais-PR (25⒉ ' S; 4042' $\mathrm{W} ; 930 \mathrm{~m}$ de altitude). O clima correspondente à região é o Cfb (Köppen), cujas características são: subtropical super úmido, mesotérmico com verões frescos e geadas severas demasiadamente frequentes, sem estação seca definida. O solo em análise química e física prévia possuía: $\mathrm{pH} \mathrm{SMP}=6,6 ; \mathrm{Al}^{+3}=0,0 \mathrm{cmol}_{\mathrm{c}}$ $\mathrm{dm}^{-3} ; \mathrm{H}^{+}+\mathrm{Al}^{+3}=3,2 \mathrm{cmol}_{\mathrm{c}} \mathrm{dm}^{-3} ; \mathrm{Ca}^{+2}=$ $9,6 \mathrm{cmol}_{\mathrm{c}} \mathrm{dm}^{-3} ; \mathrm{Mg}^{+2}=5,5$ e $\mathrm{K}^{+}=1,59$ $\mathrm{cmol}_{\mathrm{c}} \mathrm{dm}^{-3} ; \mathrm{P}=159 \mathrm{mg} \mathrm{dm}^{-3} ; \mathrm{C}=36,5 \mathrm{~g}$ $\mathrm{dm}^{-3}$; saturação de bases $=84 \%$ e teor de argila $=400 \mathrm{~g} \mathrm{~kg}^{-1}$.

Os tratamentos foram constituídos de solo coberto com uma camada de 5 $\mathrm{cm}$ de acículas de pinus, solo coberto com plástico preto e a testemunha sem cobertura. As coberturas foram colocadas no momento do plantio. O delineamento experimental utilizado foi blocos ao acaso em arranjo de parcelas subdivididas no tempo com seis repetições e 20 plantas por parcela. As parcelas foram constituídas por canteiros de 1,5 x 1,2 m, distanciados $1 \mathrm{~m}$ entre si. O espaçamento de plantio foi $0,3 \times 0,3 \mathrm{~m}$, resultando numa população de 36.363 plantas $\mathrm{ha}^{-1}$. Nas parcelas testaram-se os tipos de cobertura e nas subparcelas, as colheitas realizadas aos 84, 134 e 191 dias após o plantio.

As mudas foram produzidas em bandejas de poliestireno expandido com 128 células, usando sementes adquiridas no comércio. O substrato utilizado foi o Plantmax HT® e a semeadura foi realizada em setembro de 2005 . O transplante foi realizado em 21 de novembro de 2005, quando as mudas possuíam em média quatro folhas definitivas.

Os tratos culturais consistiram em irrigações por aspersão em todo o experimento, feitas sempre que necessárias e capinas periódicas para controle de plantas invasoras nas parcelas da testemunha e entre parcelas. Nas parcelas dos tratamentos com cobertura morta e plástico preto, as plantas invasoras foram retiradas manualmente, apenas nas primeiras semanas após o transplante. Não foi realizada adubação e nenhum controle fitossanitário contra insetos e doenças.

A colheita consistiu no corte de todas as plantas das subparcelas feito a $10 \mathrm{~cm}$ do solo (Blank et al., 2005b), sempre no período da manhã. Avaliou-se a massa fresca e seca da planta, sendo a massa seca obtida após secagem em estufa a $65^{\circ} \mathrm{C}$ até massa constante. Também foi avaliada a mortalidade das plantas para cada tipo de cobertura e em cada época de colheita. Para estimar a massa fresca e seca por hectare, a massa obtida por planta foi multiplicada pela população de plantas estimada por hectare, levando-se em consideração a mortalidade ocorrida em cada parcela. O rendimento de óleo essencial foi obtido pela multiplicação da massa seca estimada por hectare pelo teor de óleo essencial encontrado para cada parcela.

A extração do óleo essencial foi realizada a partir de folhas frescas retiradas de todas as plantas da parcela. Foram utilizadas as folhas mais jovens e inteiras, visando preservar os tricomas. A extração foi realizada por hidrodestilação, sendo colocadas 100 $\mathrm{g}$ de folhas em balões de vidro com um litro de água destilada. $\mathrm{O}$ processo foi realizado durante quatro horas, sendo o óleo essencial recuperado pelo aparelho de Clevenger e retirado por meio de micropipeta volumétrica com ajuste de 10 a $100 \mu \mathrm{L}$.

Os dados obtidos foram submetidos à análise de variância e as médias comparadas pelo teste de Duncan, a 5\% de probabilidade, utilizando o software SANEST.

\section{RESULTADOS E DISCUSSÃO}

Não houve interação entre os fatores estudados para todas as características, sendo o efeito da cobertura do solo independente da colheita realizada. A produção de massa fresca e seca por planta e por hectare não diferiu entre as coberturas de solo (Tabela 1), mesmo com o uso da acículas de pinus, que é uma cobertura orgânica e poderia ter contribuído pelo fornecimento de nutrientes. Estima-se que os teores de nutrientes presentes nas acículas de pinus são aproximadamente 11 a $16 \mathrm{~g} \mathrm{~kg}^{-1}$ de nitrogênio, 6 a $10 \mathrm{~g} \mathrm{~kg}^{-1}$ de potássio, 3 a $5 \mathrm{~g} \mathrm{~kg}^{-1}$ de cálcio, 1,3 a $2 \mathrm{~g} \mathrm{~kg}^{-1} \mathrm{de}$ magnésio, 1,3 a 1,6 $\mathrm{g} \mathrm{kg}^{-1}$ de enxofre e 0,8 a $1,4 \mathrm{~g} \mathrm{~kg}^{-1}$ de fósforo (Gonçalves, 1995). Entretanto, devido à sua decomposição ser muito lenta, a liberação de nutrientes não deve ter sido significativa, pois na terceira colheita a maior parte da cobertura ainda estava íntegra. Também não foi observada deficiência visual de nitrogênio nas plantas, que poderia ter ocorrido pela sua imobilização durante a decomposição do material orgânico.

Apesar do uso das coberturas não proporcionarem aumentos significativos para a melissa no presente trabalho, a cobertura morta de palha na quantidade de $5 \mathrm{t} \mathrm{ha}^{-1}$ proporcionou ganhos de $23,1 \%$ na massa seca e $19,9 \%$ na produção de óleo essencial de Mentha arvensis, quando comparado com o solo descoberto, atingindo como média de dois anos, $122,5 \mathrm{~kg} \mathrm{ha}^{-1}$ de óleo essencial por ano (Saxena \& Singh, 1996). Também no cultivo de $M$. arvensis, Singh et al. (2000) obtiveram melhor eficiência e economia no manejo de plantas invasoras, com a utilização de cobertura morta de palha $\left(7,5 \mathrm{tha}^{-1}\right)$ aplicada 35 dias após o plantio em combinação com a aplicação de herbicida pré-emergente.

Os resultados do rendimento de 
Tabela 1. Massa fresca e seca por planta, massa fresca e seca por hectare e mortalidade de Melissa officinalis, sob efeito de diferentes coberturas de solo, em três épocas de colheita (fresh and dried biomass per plant, fresh and dried biomass per hectare and mortality of Melissa officinalis, planted under different soil mulching on three harvest dates). Pinhais, UFPR, 2006.

\begin{tabular}{lccccc}
\hline $\begin{array}{c}\text { Parcelas } \\
\text { (coberturas de solo) }\end{array}$ & $\begin{array}{c}\text { Massa fresca } \\
\left(\mathbf{g ~ p l a n t a}^{-1} \mathbf{1}^{\mathbf{1}}\right.\end{array}$ & $\begin{array}{c}\text { Massa seca } \\
\left(\mathbf{g ~ p l a n t a}^{-1}\right)\end{array}$ & $\begin{array}{c}\text { Massa fresca } \\
\left(\mathbf{k g ~ h a}^{-1}\right)\end{array}$ & $\begin{array}{c}\text { Massa seca } \\
\left(\mathbf{k g ~ h a}^{-1}\right)\end{array}$ & $\begin{array}{c}\text { Mortalidade } \\
(\%)\end{array}$ \\
\hline Testemunha & $158,5 \mathrm{a}^{2}$ & $27,7 \mathrm{a}$ & $5735 \mathrm{a}$ & $1004 \mathrm{a}$ & $0,8 \mathrm{~b}$ \\
Acículas de pinus & $152,6 \mathrm{a}$ & $27,5 \mathrm{a}$ & $5641 \mathrm{a}$ & $990 \mathrm{a}$ & $1,7 \mathrm{~b}$ \\
Plástico preto & $150,6 \mathrm{a}$ & $27,4 \mathrm{a}$ & $4941 \mathrm{a}$ & $898 \mathrm{a}$ & $10,2 \mathrm{a}$ \\
\hline CV (\%) & 17,4 & 15,4 & 18,3 & 15,6 & 51,5 \\
\hline Subparcelas (colheitas) & & & & $4,2 \mathrm{a}$ \\
\hline 84 dias & $151,5 \mathrm{~b}$ & $27,7 \mathrm{~b}$ & $5337 \mathrm{~b}$ & $976 \mathrm{~b}$ & $4,2 \mathrm{a}$ \\
134 dias & $182,8 \mathrm{a}$ & $32,5 \mathrm{a}$ & $6369 \mathrm{a}$ & $1135 \mathrm{a}$ & $4,4 \mathrm{a}$ \\
\hline CV dias $(\%)$ & $127,4 \mathrm{~b}$ & $22,4 \mathrm{c}$ & $4611 \mathrm{~b}$ & $781 \mathrm{c}$ & 27,3 \\
\hline
\end{tabular}

${ }^{1}$ Dados transformados em raiz de $\mathrm{x}+1$ (data were transformed on root of $\mathrm{x}+1$ ); ${ }^{2}$ Médias seguidas pela mesma letra nas colunas não diferem significativamente pelo teste de Duncan a 5\% de probabilidade (means followed by the same letter in the column did not differ by Duncan test at $5 \%$ of probability).

biomassa do presente experimento diferem dos obtidos por Mendonça et al. (2005), que também estudaram o efeito da cobertura do solo com plástico preto no cultivo de Melissa officinalis em Sergipe e obtiveram rendimentos superiores de massa seca de folhas na primeira e segunda colheitas em relação ao solo sem cobertura. Os rendimentos da primeira colheita foram semelhantes aos obtidos neste experimento, mas na segunda colheita foram inferiores, sendo de 0,75 tha $^{-1}$ com o plástico e 0,53 tha $^{-1}$ sem cobertura. Em estudo com diversas espécies de plantas aromáticas, incluindo a Melissa officinalis, Galambosi \& Szebeni-Galambosi (1992) obtiveram aumento de produtividade de 20 a $40 \%$ e redução de 65 a $80 \%$ na mão-de-obra para controle de plantas invasoras, com o uso da cobertura do solo com plástico preto. Entretanto, essa prática dificultou a fertilização dos plantios.

As coberturas utilizadas, apesar de não proporcionarem aumentos significativos de produtividade, reduziram a ocorrência de plantas invasoras, sendo necessária apenas a limpeza manual daquelas que germinaram junto às mudas de melissa, nos furos do plástico preto. Já na cobertura com acículas de pinus, houve emergência de plantas invasoras, provavelmente pela camada aplicada não ter sido espessa o suficiente para impedir totalmente a incidência de luz sobre o solo. Na testemunha, foram realizadas cinco capinas desde o plantio até a primeira colheita. Entretanto, após esse período não foram necessárias mais capinas já que a melissa havia coberto todo o solo do canteiro. Desta forma, a cobertura do solo torna-se vantajosa no sentido de reduzir a mão-de-obra necessária para limpeza das plantas invasoras, mas sua aplicação irá depender da ponderação entre os custos da sua instalação e da mão-de-obra para capina.

$\mathrm{Na}$ cobertura com plástico preto houve maior mortalidade das plantas (Tabela 1), o que pode estar relacionado ao aumento da temperatura nessa cobertura pela incidência direta dos raios solares sobre a superfície preta. O plástico preto a pleno sol fica muito quente e pode ter causado a queima das mudas novas, que poderiam estar encostadas nele. A mortalidade de plantas apenas ocorreu significativamente após o plantio, antes da primeira colheita, pois após o desenvolvimento das plantas, elas cobriram totalmente o plástico preto não ocorrendo mais esse aquecimento excessivo.

$\mathrm{O}$ rendimento de massa seca por planta foi superior ao obtido por Blank et al. (2005b) que cultivou a Melissa officinalis no Sergipe e obtiveram em média $11,98 \mathrm{~g}$ planta $^{-1}$ na segunda colheita realizada oito semanas após a primeira. Neste experimento, a média na segunda colheita, realizada sete semanas após a primeira, foi de 32,5 $\mathrm{g}_{\text {planta }}{ }^{-1}$.
Esse rendimento foi obtido com sistema de irrigação por aspersão, enquanto no trabalho de Blank et al. (2005b) o sistema de irrigação foi por gotejamento sob o plástico. $\mathrm{O}$ fato de não haver diferença entre as coberturas comprova que não houve prejuízo quando ao fornecimento de água para as plantas com a cobertura plástica. Aqueles autores concluíram por recomendar o segundo corte, onze semanas após o primeiro, quando obtiveram em média 20,5 $\mathrm{g}_{\text {planta }}{ }^{-1}$, e não foi possível realizar outros cortes pela elevada mortalidade das plantas. Provavelmente, pela origem européia da melissa, a espécie encontre condições mais favoráveis ao crescimento no sul do Brasil, apenas ficando limitada à colheita durante o inverno, conforme ocorreu no presente experimento na terceira colheita, que foi significativamente inferior à segunda (Tabela 1), devido ao reduzido crescimento das plantas.

A redução de produtividade na terceira colheita deve estar relacionada a fatores climáticos, pois no mês de maio observou-se redução da temperatura e da radiação solar (Figura 1). Como o experimento foi irrigado, as variações na precipitação não devem ter influenciado significativamente nessa resposta.

Quanto ao rendimento de óleo essencial, também não se constatou diferença entre os tipos de cobertura de solo testados (Tabela 2). Resultado diferente foi obtido com palmarosa 


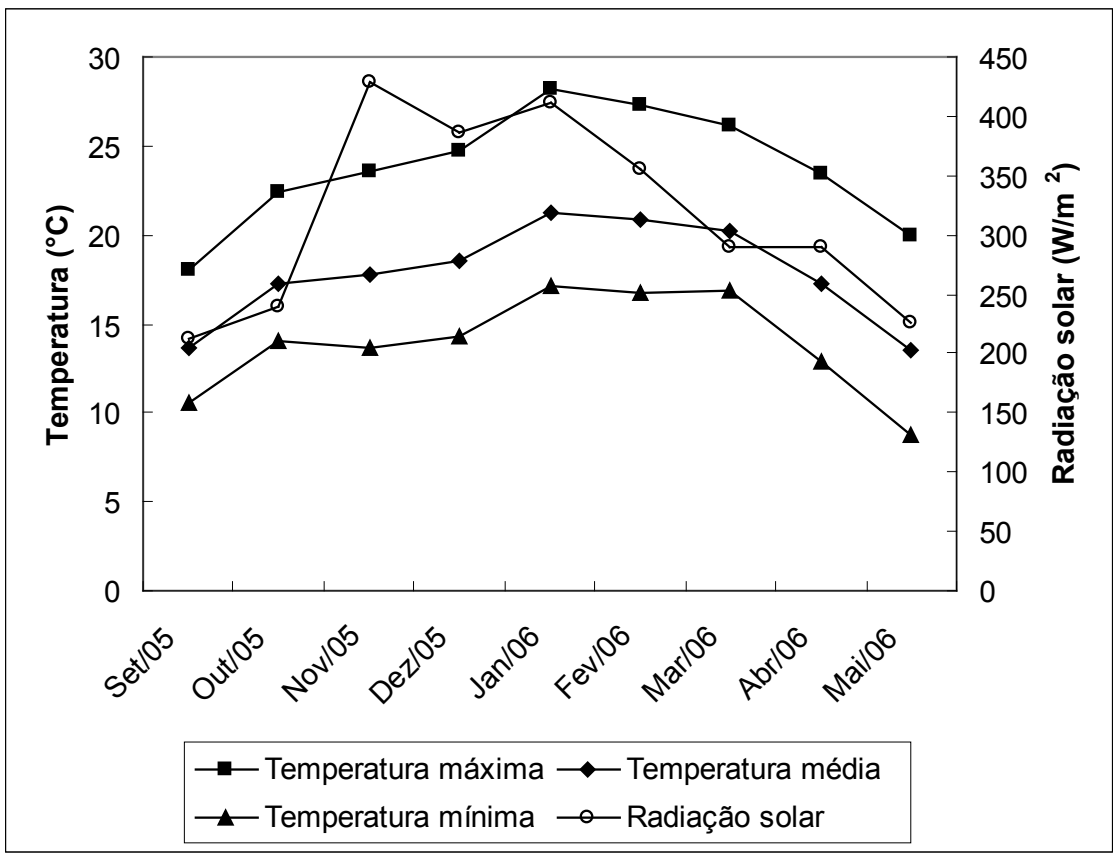

Figura 1. Variação mensal da temperatura média máxima, média e mínima e da radiação solar média no período de setembro de 2005 a maio de 2006 (variation of monthly average maximum temperature, average and minimum and average solar radiation in the period of September 2005 to May 2006). Pinhais, UFPR, 2006. Fonte: SIMEPAR, 2009.

Tabela 2. Rendimento ( $\left.\mathrm{L} \mathrm{ha}^{-1}\right)$ e teor de óleo essencial (\%) de Melissa officinalis, sob efeito de diferentes coberturas de solo, em três épocas de colheita (essential oil yield ( $\mathrm{L} \mathrm{ha}^{-1}$ ) and production (\%) of Melissa officinalis, with different mulching at three harvest date). Pinhais, UFPR, 2006.

\begin{tabular}{|c|c|c|}
\hline $\begin{array}{c}\text { Parcelas (coberturas de } \\
\text { solo) }\end{array}$ & $\begin{array}{l}\text { Rendimento de óleo } \\
\text { essencial }\left(\mathrm{L} \mathrm{ha}^{-1}\right)^{1}\end{array}$ & $\begin{array}{l}\text { Teor de óleo essencial } \\
(\%)^{1}\end{array}$ \\
\hline Testemunha & $3,04 \mathrm{a}^{2}$ & $0,30 \mathrm{a}$ \\
\hline Acículas de pinus & $2,67 \mathrm{a}$ & $0,26 \mathrm{a}$ \\
\hline Plástico preto & $2,32 \mathrm{a}$ & $0,25 \mathrm{a}$ \\
\hline $\mathrm{CV}(\%)$ & 13,6 & 3,7 \\
\hline \multicolumn{3}{|l|}{ Subparcelas (colheitas) } \\
\hline 84 dias & $4,63 \mathrm{a}$ & $0,48 \mathrm{a}$ \\
\hline 134 dias & $2,97 \mathrm{~b}$ & $0,28 \mathrm{~b}$ \\
\hline 191 dias & $0,43 \mathrm{c}$ & $0,05 \mathrm{c}$ \\
\hline $\mathrm{CV}(\%)$ & 19,9 & 6,1 \\
\hline \multicolumn{3}{|c|}{$\begin{array}{l}{ }^{1} \text { Dados transformados em raiz de } \mathrm{x}+1 \text { (data were transformed on root of } \mathrm{x}+1 \text { ); }{ }^{2} \text { Médias } \\
\text { seguidas pela mesma letra nas colunas não diferem significativamente pelo teste de Duncan } \\
\text { a } 5 \% \text { de probabilidade (means followed by the same letter in the column do not differ by } \\
\text { Duncan test at } 5 \% \text { of probability). }\end{array}$} \\
\hline
\end{tabular}

(Cymbopogon martinii var. motia), com vários tratamentos para o controle de plantas invasoras, incluindo o uso de herbicida, adubação verde e cobertura morta orgânica. Singh \& Singh (1997) encontraram maior rendimento de óleo essencial na safra 1986/1987, com o uso de 7,5 t ha-1 de resíduo da destilação da própria palmarosa, que proporcionou a obtenção de $184,3 \mathrm{~kg} \mathrm{ha}^{-1}$, comparados com 94,9 kg ha-1, sem controle de plan- entre 0,06 e $0,375 \%$. Mendonça et al. (2005) obtiveram teores semelhantes aos encontrados neste experimento, na primeira colheita e maiores na segunda, atingindo $0,85 \%$ com a cobertura do solo com plástico. Blank et al. (2005a) obtiveram uma grande variação no teor de óleo essencial de melissa em função do horário de colheita, obtendo $2,37 \%$ em folha seca, na colheita realizada às 17 horas.

O teor de óleo essencial reduziu significativamente da primeira para a terceira colheita, de $0,48 \%$ para $0,05 \%$. A redução da temperatura e da radiação solar (Figura 1), que ocorreu em Pinhais, a partir do mês de janeiro até maio, deve ter influenciado negativamente o metabolismo secundário da melissa e o acúmulo de óleo essencial. A temperatura média mensal reduziu $7,8^{\circ} \mathrm{C}$ de janeiro até maio e a radiação solar reduziu 185,2 $\mathrm{W} \mathrm{m}^{-2}$. Esse fato também foi observado em diversos genótipos de Mentha cultivados no mesmo local, onde, na colheita realizada no inverno, o teor de óleo essencial foi inferior ao encontrado no verão e as espécies Mentha suaveolens, cv. Hillary Sweet Lemon Mint, Mentha arvensis cv. Banana Mint e Mentha x piperita. cv. Grapefruit Mint apresentaram reduções maiores de 50\% (Deschamps et al., 2008).

Concluiu-se que a cobertura do solo com acículas de pinus e plástico preto não interferiram no rendimento de biomassa e de óleo essencial no cultivo irrigado por aspersão de melissa, ficando a sua utilização na dependência de um estudo para avaliar se há vantagem econômica pela redução da mão-de-obra para capina. $\mathrm{O}$ crescimento e o acúmulo de óleo essencial da melissa reduzem nas colheitas realizadas no outono na região de Pinhais.

\section{AGRADECIMENTOS} tratamentos resultou em maior retorno financeiro com a aplicação da cobertura morta orgânica.

O teor de óleo essencial obtido na primeira colheita pode ser considerado alto $(0,48 \%$ massa seca), uma vez que Martins \& Pastori (2004) obtiveram $0,21 \%$ para a mesma espécie e Sarer $\&$ Kökdil (1991) relataram que o teor de óleo essencial de melissa varia
Os autores agradecem à Secretaria de Estado de Ciência e Tecnologia (SETI)/Governo do Estado do Paraná, pelo apoio financeiro e concessão de bolsa para as alunas de graduação, ao CNPq, pela bolsa de Produtividade em Pesquisa do CNPq do primeiro autor e ao SIMEPAR, pelos dados climáticos. 


\section{REFERÊNCIAS}

ARAÚJO AP; NEGREIROS MZ; LEITÃO MMVBR; PEDROSA JF; BEZERRA NETO F; ESPÍNOLA SOBRINHO J; FERREIRA RLF; NOGUEIRA ICC. 2003. Rendimento de melão amarelo cultivado em diferentes tipos de cobertura do solo e métodos de plantio. Horticultura Brasileira 21: 123-126.

BLANK AF; FONTES SM; CARVALHO FILHO JLS; ALVES PB; SILVA-MANN R; MENDONÇA MC; ARRIGONI-BLANK MF; RODRIGUES MO. 2005a. Influência do horário de colheita e secagem de folhas no óleo essencial de melissa (Melissa officinalis L.) cultivada em dois ambientes. Revista Brasileira de Plantas Medicinais 8: 73-78.

BLANK AF; FONTES SM; OLIVEIRA AS; MENDONÇA MC; SILVA-MANN R; ARRIGONI-BLANK MF. 2005b. Produção de mudas, altura e intervalo de corte em melissa. Horticultura Brasileira 23: 780-784.

CORRÊA JUNIOR C; SCHEFFER MC. 2004. Produção de plantas medicinais, condimentares e aromáticas no Estado do Paraná. In: CORRÊA JUNIOR C; GRAÇA LR; SCHEFFER MC (eds). Complexo agroindustrial das plantas medicinais, aromáticas e condimentares no Estado do Paraná: diagnóstico e perspectivas. Curitiba: Sociedade Paranaense de Plantas Medicinais, EMATER-PR; Colombo: Embrapa Florestas, p. 48-68.

CORRÊA TM; PALUDO SK; RESENDE FV; OLIVEIRA PSR. 2003. Adubação química e cobertura morta em alho proveniente de cultura de tecidos. Horticultura Brasileira
21: 601-604.

DESCHAMPS C; ZANATTA JL; BIZZO HR; OLIVEIRA MC; ROSWALKA LC. 2008. Avaliação sazonal do rendimento de óleo essencial em espécies de menta. Ciência e Agrotecnologia 32: 725-730.

GALAMBOSI B; SZEBENI-GALAMBOSI Z. 1992. The use of black plastic mulch and ridges in the production of herbicide free herbs. Acta Horticulturae 306: 353-356.

GOLÇALVES JLM. 1995. Recomendações de adubação para Eucalyptus, Pinus e espécies típicas da Mata Atlântica. Documentos Florestais 15:1-23.

LORENZI H; MATOS FJA. 2002. Plantas medicinais do Brasil: nativas e exóticas cultivadas. Nova Odessa: Instituto Plantarum. 512p.

MARTINS MBG; PASTORI AP. 2004. Anatomia foliar com ênfase nos tricomas secretores e análise cromatográfica do óleo essencial de Melissa officinalis L. (Lamiaceae). Revista Brasileira de Plantas Medicinais 6: 77-82.

MENDONÇA MC; SANTOS MF; SIMÕES RA; SILVA-MANN R; BLANK AF. 2005. Production and entomofauna associated to lemon balm (Melissa officinalis L.) cultivated with synthetic mulch. Revista Brasileira de Plantas Medicinais 8: 63-67.

MIRANDANO; MEDEIROS JF; NASCIMENTO IB; ALVES LP. 2003. Produtividade e qualidade de frutos de melão em resposta à cobertura do solo com plástico preto e ao preparo do solo. Horticultura Brasileira 21: 490-493.

NEGREIROS MZ; COSTA FA; MEDEIROS JF; LEITÃO VBRMM; BEZERRA NETO F;
ESPÍNOLA SOBRINHO J. 2005. Rendimento e qualidade do melão sob lâminas de irrigação e cobertura do solo com filmes de polietileno de diferentes cores. Horticultura Brasileira 23: 773-779.

QUEIROGA RCF; NOGUEIRA ICC; BEZERRA NETO F; MOURA ARB; PEDROSA JF. 2002. Utilização de diferentes materiais como cobertura morta do solo no cultivo de pimentão. Horticultura Brasileira 20: 416-418.

SARER E; KÖKDIL G. 1991. Constituents of the essential oil from Melissa officinalis. Planta Medica 57: 89-90.

SAXENAA; SINGH JN. 1996. Yield and nitrogen uptake of japanese mint (Mentha arvensis) under various moisture regimes, mulch appplication and nitrogen fertilization. Journal of Medicinal and Aromatic Plant Sciences 18: 477-480.

SIMEPAR - Instituto Tecnológico SIMEPAR. Temperatura média máxima, média e mínima e radiação solar média. Curitiba, Maio de 2009. Arquivo eletrônico Word for Windows. 2009.

SINGH M; SINGH A. 1997. Efficacy and economics of herbicide, organic mulch and intercropping for weed management in palmarosa (Cymbopogon martinii var. motia). Journal of Medicinal and Aromatic Plant Sciences 19: 1028-1033.

SINGH M; SINGH A; KOTHARI SK; VERMA BS; SINGH DV. 2000. Integrated weed management in menthol mint (Mentha arvensis L.). Journal of Medicinal and Aromatic Plant Sciences 22: 456-459. 